\title{
Práticas de manejo integradas para produção de arroz irrigado
}

\author{
Carlos Henrique Paim Mariot(1), Vladirene Macedo Vieira(2), Paulo Regis Ferreira da Silva(2), \\ Valmir Gaedke Menezes ${ }^{(1)}$, Camilo Feliciano de Oliveira(1) e Thais Fernanda Stella de Freitas ${ }^{(1)}$
}

\begin{abstract}
(1)Instituto Rio Grandense do Arroz, Divisão de Pesquisa, Avenida Bonifácio Carvalho Bernardes, no 1.494, Caixa Postal 29, CEP $94930-030$ Cachoeirinha, RS. E-mail: carlos-mariot@irga.rs.gov.br, vmgaedke@yahoo.com.br, camilofeliciano@yahoo.com.br, thais-freitas@irga.rs.gov.br (2)Universidade Federal do Rio Grande do Sul, Faculdade de Agronomia, Departamento de Plantas de Lavoura, Caixa Postal 15100, CEP $90001-970$ Porto Alegre, RS.

E-mail: vladirene@gmail.com, paulo.silva@ufrgs.br
\end{abstract}

Resumo - O objetivo deste trabalho foi realizar a avaliação técnica e financeira do arroz irrigado (Oryza sativa) em função da integração de práticas de manejo da cultura. O experimento foi conduzido em Cachoeirinha, RS. O delineamento experimental foi o de blocos ao acaso, com parcelas subsubdivididas, com quatro repetições. As estações de crescimento (2003/2004, 2004/2005 e 2006/2007) foram locadas na parcela principal, as épocas de semeadura (preferencial e tardia), nas subparcelas e os sistemas de práticas de manejo (baixo, médio, alto e muito alto), nas subsubparcelas. Os sistemas de práticas de manejo variaram quanto à densidade de semeadura, à adubação de base e de cobertura, à dose de herbicida e aos manejos da adubação nitrogenada de cobertura e da irrigação. A resposta em produtividade de grãos e em retorno financeiro do arroz irrigado à melhoria nas práticas de manejo foi maior na época de semeadura preferencial, no final de outubro, do que na semeadura tardia, na primeira semana de dezembro. Na época preferencial, o retorno financeiro aumentou com a melhoria nas práticas de manejo, por causa do aumento da receita, proporcionado pela maior produtividade de grãos.

Termos para indexação: Oryza sativa, análise financeira, práticas culturais, produtividade de grãos.

\section{Integrated management practices for lowland rice production}

\begin{abstract}
The objective of this work was to perform a technical and financial evaluation of integrated management practices for lowland rice (Oryza sativa). The experiment was carried out in Cachoeirinha, in the state of Rio Grande do Sul, Brazil. A randomized block design with split-split plots with four replications was used. The three growing seasons (2003/2004, 2004/2005, and 2006/2007) were the main plots, the sowing dates (preferential and late) were the split plots, and the management practice systems (low, average, high and very high) were the split-split plots. The management practice systems varied in terms of seeding rate, fertilizer rate, herbicide rate, nitrogen fertilizer topdress management, and irrigation management. The grain yield and financial return responses to the improvement of management practices were greater at the preferential sowing date, at the end of October, than on the first week of December. At the preferential sowing date, the financial return increased with the improvement of management practices, due to the increased income resulting from the higher grain yield.
\end{abstract}

Index terms: Oryza sativa, financial analysis, management strategies, grain yield.

\section{Introdução}

Para a obtenção de rendimentos elevados e estáveis na cultura do arroz irrigado, a escolha da melhor época de semeadura é uma das principais práticas de manejo, por aumentar a probabilidade de a planta, em sua fase crítica, escapar de condições climáticas adversas (Sociedade Sul-Brasileira de Arroz Irrigado, 2007). As semeaduras realizadas fora do período recomendado expõem as plantas a menor taxa de radiação solar e a baixas temperaturas do ar durante a fase reprodutiva, o que reflete em menores produtividades de grãos (Menezes et al., 2004).
Na maior parte da área cultivada com arroz irrigado no Rio Grande do Sul, o período recomendado para semeadura é muito restrito, sendo de no máximo 50 dias. $\mathrm{O}$ excesso de precipitação pluvial nos meses de agosto e setembro e a drenagem deficiente dos solos muitas vezes impedem a semeadura no período recomendado (Freitas et al., 2008).

Outro fator importante associado à época de semeadura do arroz é a resposta à adubação nitrogenada (Slaton et al., 2003). A eficiência de uso de nitrogênio (N) é maior quando ocorre alta taxa de radiação solar nos períodos reprodutivo e de formação e início de enchimento de grãos (Fagi \& De Datta, 1981), 
condição que é alcançada quando a semeadura é feita na época preferencial (Sociedade Sul-Brasileira de Arroz Irrigado, 2007).

Além dos fatores intrínsecos à planta e das condições edafoclimáticas da região de cultivo, o manejo da cultura interfere no rendimento de fitomassa, na interceptação da radiação solar, no acúmulo de fotoassimilados e, consequentemente, na produtividade de grãos (Argenta et al., 2003). Ainda não se dispõe de trabalhos de pesquisa com avaliação técnico-financeira do arroz irrigado em resposta ao manejo integrado de práticas culturais, em diferentes épocas de semeadura. Trabalhos já foram realizados para avaliar a resposta a fatores isolados, como a adubação nitrogenada e a densidade de semeadura, tanto no sistema convencional de semeadura (Mariot et al., 2003) como no pré-germinado (Carmona et al., 2008). Esses estudos foram realizados em apenas uma época de semeadura, e não foi avaliada a interação desse fator com as demais práticas de manejo.

A adoção de determinado sistema de produção deve levar em consideração fatores técnicos e financeiros. Um dos parâmetros utilizados para avaliação da viabilidade financeira é a margem de contribuição parcial (Iudícibus \& Marion, 1990), a qual se refere à diferença entre a receita líquida e os custos de produção selecionados. A compatibilização das análises técnica e financeira dos sistemas de produção é importante para a escolha do manejo da cultura mais adequado para uma dada época de semeadura.

O objetivo deste trabalho foi realizar a análise técnico-financeira do arroz irrigado em função da integração de práticas de manejo em duas épocas de semeadura.

\section{Material e Métodos}

OexperimentofoiconduzidonaEstaçãoExperimental doArroz do Instituto Rio Grandense doArroz(IRGA) em Cachoeirinha, região ecoclimática da Depressão Central do Rio Grande do Sul. O solo da área experimental é classificado como Gleissolo Háplico Ta distrófico típico (Santos et al., 2006). O clima da região é do tipo subtropical úmido, conforme classificação de Köppen, sendo considerado como de transição entre os tipos $\mathrm{Cfa}_{1}$ (isoterma anual inferior a $18^{\circ} \mathrm{C}$ ) e $\mathrm{Cfa}_{2}$ (isoterma anual superior a $18^{\circ} \mathrm{C}$ ). A temperatura mínima média do ar é de $9,8^{\circ} \mathrm{C}$ no mês mais frio (julho) e a máxima é de $31,6^{\circ} \mathrm{C}$ no mês mais quente (janeiro). A precipitação pluvial média anual é de $1.425 \mathrm{~mm}$ e a disponibilidade de radiação solar máxima é de $2.106 \mathrm{~J} \mathrm{~cm}^{-2}$ dia $^{-1}$ no mês de dezembro. Os dados referentes à temperatura média do ar, à radiação solar e à precipitação pluvial nas três estações de crescimento encontram-se na Figura 1.

$\mathrm{O}$ arroz irrigado foi conduzido no sistema de cultivo mínimo, em sucessão ao pousio no inverno. A cultivar de arroz utilizada nos três anos foi a IRGA 420, de ciclo médio, com alto potencial produtivo (Sociedade Sul-Brasileira de Arroz Irrigado, 2007). Os tratamentos constaram de quatro sistemas de práticas de manejo (baixo, médio, alto e muito alto), duas épocas de semeadura (uma considerada preferencial e a outra tardia) e três estações de crescimento (2003/2004, 2004/2005 e 2006/2007) (Tabela 1). As datas de semeadura na época preferencial foram 5 de novembro de 2003, 29 de outubro de 2004 e 27 de outubro de 2006, e na época tardia foram 3 de dezembro nos anos de 2003 e 2004 e 13 de dezembro de 2006.

Os sistemas de práticas de manejo diferenciaram-se quanto à densidade de semeadura, adubação de base e de cobertura e à dose de herbicida utilizada (Tabela 1). Houve também diferença no manejo da adubação nitrogenada em cobertura e da irrigação. Sob sistemas de práticas de manejo baixo, a adubação nitrogenada foi aplicada em dose única, no estádio de diferenciação do primórdio da panícula (estádio $\mathrm{V}_{9}$, conforme escala de desenvolvimento proposta por Counce et al., 2000), e a entrada da água de irrigação ocorreu 30 dias após a emergência das plantas de arroz (estádio $\mathrm{V}_{6}$ ). No sistema de práticas de manejo médio, a adubação nitrogenada foi feita em duas épocas, com metade da dose após a entrada da água de irrigação, que ocorreu 20 dias após a emergência do arroz (estádio $\mathrm{V}_{4}$ ), e metade da dose no estádio de diferenciação do primórdio da panícula. Sob sistemas de práticas de manejo alto e muito alto, dois terços da dose da adubação nitrogenada foram aplicados antes da entrada da água de irrigação (estádio $\mathrm{V}_{3}$ ) e o restante antes da diferenciação do primórdio da panícula (estádio $\mathrm{V}_{8}$ ). Nesses dois sistemas, o manejo da cultura seguiu as recomendações técnicas da Sociedade Sul-Brasileira de Arroz Irrigado (2007). A caracterização de cada sistema de práticas de manejo quanto aos insumos utilizados e às operações realizadas encontra-se na Tabela 1. Na terceira estação de crescimento, foram utilizados herbicidas com maior eficiência no controle de plantas daninhas, liberados recentemente para uso.

O delineamento experimental foi o de blocos ao acaso, com parcelas subsubdivididas, com quatro repetições. A 
estação de crescimento foi locada na parcela principal, a época de semeadura, nas subparcelas e os sistemas de práticas de manejo, nas subsubparcelas. Os tratamentos foram aplicados sempre nas mesmas subsubparcelas, para se poder avaliar os efeitos dos diferentes sistemas de práticas de manejo na fertilidade do solo ao final de três estações de crescimento. Cada subsubparcela foi formada por 12 linhas de $6 \mathrm{~m}$ de comprimento, com espaçamento entre linhas de $17,5 \mathrm{~cm}$.

A produtividade de grãos foi avaliada nas dez linhas centrais de cada unidade experimental. Descontando-se $50 \mathrm{~cm}$ em cada extremidade da subsubparcela, a área útil totalizou $8,75 \mathrm{~m}^{2}$. Os dados foram submetidos à análise de variância e, quando ocorreu significância, as médias foram comparadas pelo teste de Duncan.

$\mathrm{Na}$ análise financeira utilizou-se o indicador denominado margem de contribuição parcial (Iudícibus \& Marion, 1990). Essa análise refere-se à receita líquida subtraída dos custos operacionais. Neste trabalho foram considerados apenas os custos que se alteraram conforme a variação dos sistemas de práticas de manejo aplicados. A margem de contribuição parcial pode ser considerada como a parcela da receita destinada ao pagamento dos demais custos e das despesas fixas e à formação do lucro líquido do exercício (Iudícibus \& Marion, 1990).

Para determinação da margem de contribuição parcial foram levantados os custos da aquisição de insumos, da aplicação mecanizada dos insumos e das operações de colheita, transporte e secagem (Tabela 2). Utilizouse como base o modelo de determinação do custo de produção desenvolvido pelo IRGA (2006). A apuração dos preços foi feita utilizando-se as pesquisas periódicas de preços para formação do custo de produção ponderado do arroz irrigado no Rio Grande do Sul, realizadas pelo IRGA nas principais revendas de insumos e máquinas do Estado, e considerando-se o preço médio no ano. Para os preços de venda do arroz em casca, considerou-se a cotação do produto com renda de $58 \times 10$, tipo 1 . Na época preferencial, a cotação foi referente à média entre março e julho e, na época tardia, à média entre maio e setembro. Em relação aos tratos culturais, foram considerados a dessecação, a semeadura, o tratamento de sementes, a aplicação de defensivos, as adubações de base e de cobertura. Excluíram-se as depreciações e o custo de oportunidade. Nas operações de colheita, transporte e secagem, considerou-se o valor médio pago por serviço terceirizado nas principais regiões produtoras de arroz do Rio Grande do Sul, mediante a mesma pesquisa de
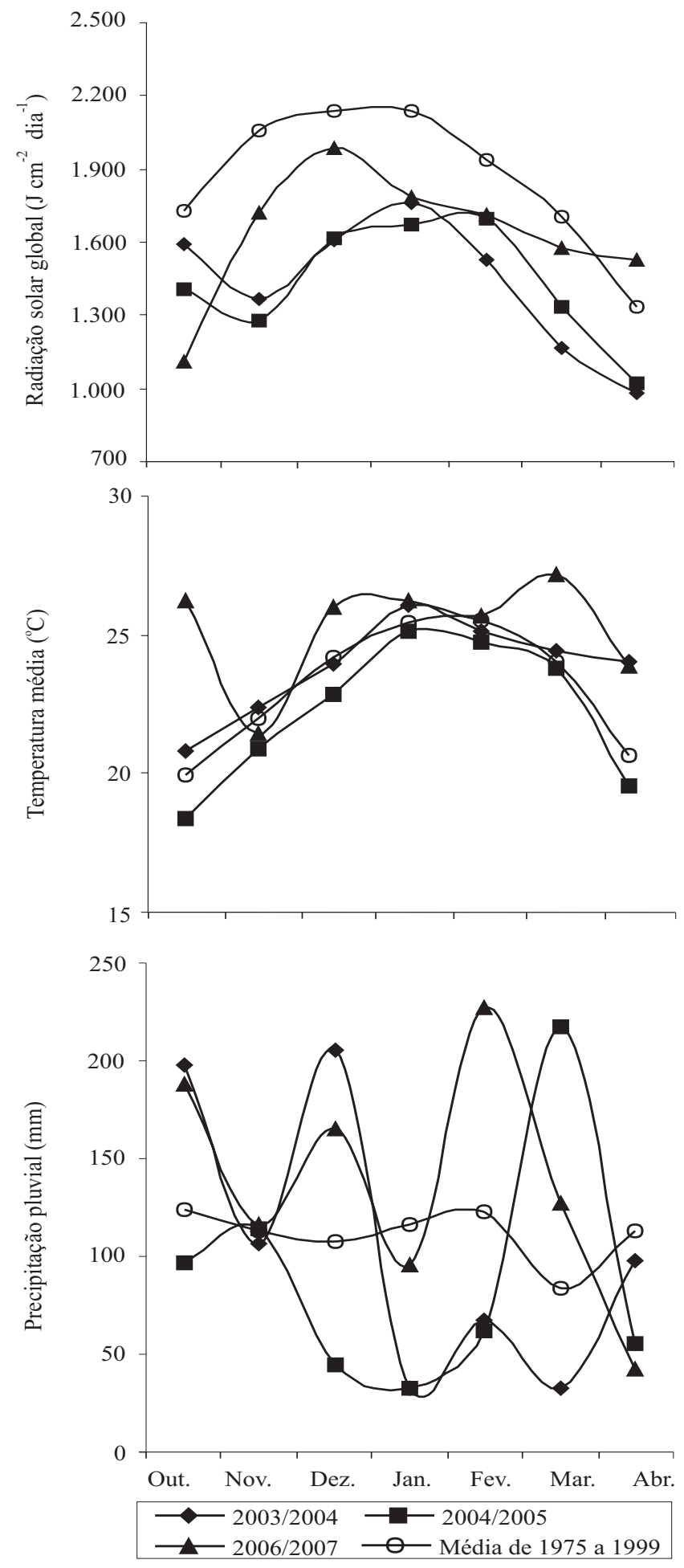

Figura 1. Radiação solar global, temperatura média do ar e precipitação pluvial mensais, relativas a três estações de crescimento (2003/2004, 2004/2005 e 2006/2007) e à média do período entre 1975 e 1999 em Cachoeirinha, RS. Dados da Fundação Estadual de Pesquisa Agropecuária do Rio Grande do Sul (Fepagro). 
Tabela 1. Insumos utilizados e operações realizadas na cultura do arroz irrigado em função do sistema de práticas de manejo, em três estações de crescimento e em duas épocas de semeadura (preferencial e tardia) em Cachoeirinha, $\mathrm{RS}^{(1)}$.

\begin{tabular}{|c|c|c|c|c|}
\hline \multirow[t]{2}{*}{ Insumos utilizados e operações realizadas } & \multicolumn{4}{|c|}{ Sistemas de práticas de manejo } \\
\hline & Baixo & Médio & Alto & Muito alto \\
\hline & \multicolumn{4}{|c|}{$2003 / 2004$} \\
\hline Sementes - cultivar Irga $420\left(\mathrm{~kg} \mathrm{ha}^{-1}\right)$ & 200 & 175 & 120 & 120 \\
\hline Adubação na semeadura $\left(\mathrm{kg} \mathrm{ha}^{-1}\right)$ & $100^{(2)}$ & $150^{(2)}$ & $300^{(2)}$ & $300^{(3)}+120$ de $\mathrm{KCl}$ \\
\hline Adubação em cobertura - ureia $\left(\mathrm{kg} \mathrm{ha}^{-1}\right)$ & 50 & 100 & 260 & 260 \\
\hline Herbicida quinclorac $\left(\mathrm{g} \mathrm{ha}^{-1} \text { de i.a. }\right)^{(4)}$ & 300 & 300 & 150 & 150 \\
\hline Herbicida propanil (g ha ${ }^{-1}$ de i.a. $)^{(4)}$ & 2.400 & 2.400 & 1.920 & 1.920 \\
\hline Herbicida pyrazosulfuron-ethyl $\left(\mathrm{g} \mathrm{ha}^{-1} \text { de i.a. }\right)^{(4)}$ & 20 & 20 & 15 & 15 \\
\hline \multicolumn{5}{|l|}{ ( } \\
\hline Sementes - cultivar Irga $420\left(\mathrm{~kg} \mathrm{ha}^{-1}\right)$ & 200 & 175 & 120 & 120 \\
\hline Adubação na semeadura $\left(\mathrm{kg} \mathrm{ha}^{-1}\right)$ & $100^{(2)}$ & $150^{(2)}$ & $300^{(2)}$ & $300^{(3)}+120$ de $\mathrm{KCl}$ \\
\hline Adubação em cobertura - ureia $\left(\mathrm{kg} \mathrm{ha}^{-1}\right)$ & 50 & 100 & 260 & 260 \\
\hline Herbicida quinclorac $\left(\mathrm{g} \mathrm{ha}^{-1} \text { de i.a. }\right)^{(4)}$ & 300 & 300 & 150 & 150 \\
\hline Herbicida propanil ( $\mathrm{g} \mathrm{ha}^{-1}$ de i.a. $)^{(4)}$ & 2.400 & 2.400 & 1.920 & 1.920 \\
\hline Herbicida pyrazosulfuron-ethyl $\left(\mathrm{g} \mathrm{ha}^{-1} \text { de i.a. }\right)^{(4)}$ & 20 & 20 & 15 & 15 \\
\hline \multicolumn{5}{|c|}{$2006 / 2007$} \\
\hline Sementes - cultivar Irga $420\left(\mathrm{~kg} \mathrm{ha}^{-1}\right)$ & 200 & 175 & 120 & 120 \\
\hline Adubação na semeadura $\left(\mathrm{kg} \mathrm{ha}^{-1}\right)$ & $100^{(2)}$ & $150^{(2)}$ & $300^{(2)}+50$ de $\mathrm{KCl}$ & $400^{(2)}+50$ de $\mathrm{KCl}$ \\
\hline Adubação em cobertura - ureia $\left(\mathrm{kg} \mathrm{ha}^{-1}\right)$ & 50 & 100 & 260 & 260 \\
\hline Herbicida penoxsulan $\left(\mathrm{g} \mathrm{ha}^{-1} \text { de i.a. }\right)^{(4)}$ & 48 & 48 & 43,2 & 43,2 \\
\hline Herbicida cyhalofop-butyl (g ha ${ }^{-1}$ de i.a. $)^{(4)}$ & 450 & 450 & 324 & 324 \\
\hline
\end{tabular}

${ }^{(1)} \mathrm{Em}$ todos os sistemas de práticas de manejo foi usado o dessecante glyphosate (2.400 $\mathrm{g} \mathrm{ha}^{-1}$ do i.a.) e o fipronil (37,5 g do i.a. por $100 \mathrm{~kg}$ de sementes $)$ no tratamento de sementes; foram realizadas as operações de semeadura (uma), aplicação de herbicida (uma), adubação de cobertura (uma no sistema de práticas de manejo baixo e duas nos demais sistemas) e colheita (uma); as semeaduras correspondentes à época preferencial foram feitas em 5/11/2003, 29/10/2004 e 27/10/2006; as semeaduras correspondentes à época tardia foram feitas em 3/12/2003, 3/12/2004 e 13/12/2006. ${ }^{(2)}$ Fórmula 5-20-30. ${ }^{(3)}$ Fórmula 8-20-26 com micronutrientes (6, 7,2, 0,201, 0,6 e 0,021 $\mathrm{kg} \mathrm{ha}^{-1}$ de Ca, S, B, Zn e Mo, respectivamente). ${ }^{(4)}$ Mistura de tanque.

Tabela 2. Quantidade e preço dos insumos utilizados na cultura do arroz irrigado em função de sistemas de práticas de manejo em três estações de crescimento e em duas épocas de semeadura (preferencial e tardia) em Cachoeirinha, $\mathrm{RS}^{(1)}$.

\begin{tabular}{|c|c|c|c|c|c|c|c|c|c|c|}
\hline \multirow[t]{2}{*}{ Insumos } & \multirow[t]{2}{*}{ Unid. } & \multirow[t]{2}{*}{$\begin{array}{l}\text { Valor } \\
\text { (R\$) }\end{array}$} & \multicolumn{4}{|c|}{$\begin{array}{l}\text { Sistemas de práticas de manejo }{ }^{(2)} \\
\text { (quantidade de produto) }\end{array}$} & \multicolumn{4}{|c|}{$\begin{array}{l}\text { Sistemas de práticas de manejo } \\
\text { (valor de aquisição }-\mathrm{R} \$ \mathrm{ha}^{-1} \text { ) }\end{array}$} \\
\hline & & & Baixo & Médio & Alto & Muito alto & Baixo & Médio & Alto & Muito alto \\
\hline & & & \multicolumn{8}{|c|}{$2003 / 2004$} \\
\hline Glyphosate & $\mathrm{L}$ & 18,10 & 5 & 5 & 5 & 5 & 91 & 91 & 91 & 91 \\
\hline Fipronil & $\mathrm{L}$ & 355,00 & 0,300 & 0,263 & 0,180 & 0,180 & 107 & 93 & 64 & 64 \\
\hline Quinclorac & $\mathrm{kg}$ & 240,00 & 0,600 & 0,600 & 0,300 & 0,300 & 144 & 144 & 72 & 72 \\
\hline Propanil & $\mathrm{L}$ & 17,00 & 5 & 5 & 4 & 4 & 85 & 85 & 68 & 68 \\
\hline Pyrazosulfuron-ethyl & $\mathrm{mL}$ & 0,82 & 80 & 80 & 60 & 60 & 66 & 66 & 49 & 49 \\
\hline Adubo $5-20-30$ & $\mathrm{t}$ & 686,00 & 0,100 & 0,150 & 0,300 & $\mathrm{n} / \mathrm{u}^{(3)}$ & 69 & 103 & 206 & $\mathrm{n} / \mathrm{u}$ \\
\hline Adubo 8-20-26 & $\mathrm{t}$ & 699,00 & $\mathrm{n} / \mathrm{u}$ & $\mathrm{n} / \mathrm{u}$ & $\mathrm{n} / \mathrm{u}$ & 0,300 & $\mathrm{n} / \mathrm{u}$ & $\mathrm{n} / \mathrm{u}$ & $\mathrm{n} / \mathrm{u}$ & 210 \\
\hline $\mathrm{KCl}$ & $\mathrm{t}$ & 880,00 & $\mathrm{n} / \mathrm{u}$ & $\mathrm{n} / \mathrm{u}$ & $\mathrm{n} / \mathrm{u}$ & 0,120 & $\mathrm{n} / \mathrm{u}$ & $\mathrm{n} / \mathrm{u}$ & $\mathrm{n} / \mathrm{u}$ & 106 \\
\hline Ureia $(46 \% \mathrm{~N})$ & $\mathrm{t}$ & 720,00 & 0,050 & 0,100 & 0,260 & 0,260 & 36 & 72 & 187 & 187 \\
\hline Sementes $^{(4)}$ & $\mathrm{kg}$ & 0,85 & 200 & 175 & 120 & 120 & 170 & 148 & 102 & 102 \\
\hline \multirow[t]{2}{*}{ Total $\left(\mathrm{R} \$ \mathrm{ha}^{-1}\right)$} & & & & & & & 766 & 802 & 839 & 948 \\
\hline & & & \multicolumn{8}{|c|}{$2004 / 2005$} \\
\hline Glyphosate & $\mathrm{L}$ & 20,00 & 5 & 5 & 5 & 5 & 100 & 100 & 100 & 100 \\
\hline Fipronil & $\mathrm{L}$ & 369,00 & 0,300 & 0,263 & 0,180 & 0,180 & 111 & 97 & 66 & 66 \\
\hline Quinclorac & $\mathrm{kg}$ & 315,00 & 0,600 & 0,600 & 0,300 & 0,300 & 189 & 189 & 95 & 95 \\
\hline Propanil & $\mathrm{L}$ & 21,00 & 5 & 5 & 4 & 4 & 105 & 105 & 84 & 84 \\
\hline Pyrazosulfuron-ethyl & $\mathrm{mL}$ & 0,87 & 80 & 80 & 60 & 60 & 69 & 69 & 52 & 52 \\
\hline Adubo $5-20-30$ & $\mathrm{t}$ & 846,00 & 0,100 & 0,150 & 0,300 & $(\mathrm{n} / \mathrm{u})$ & 85 & 127 & 254 & $\mathrm{n} / \mathrm{u}$ \\
\hline Adubo $8-20-26$ & $\mathrm{t}$ & 888,00 & $\mathrm{n} / \mathrm{u}$ & $\mathrm{n} / \mathrm{u}$ & $\mathrm{n} / \mathrm{u}$ & 0,300 & $\mathrm{n} / \mathrm{u}$ & $\mathrm{n} / \mathrm{u}$ & $\mathrm{n} / \mathrm{u}$ & 266 \\
\hline $\mathrm{KCl}$ & $\mathrm{t}$ & 885,00 & $\mathrm{n} / \mathrm{u}$ & $\mathrm{n} / \mathrm{u}$ & $\mathrm{n} / \mathrm{u}$ & 0,120 & $\mathrm{n} / \mathrm{u}$ & $\mathrm{n} / \mathrm{u}$ & $\mathrm{n} / \mathrm{u}$ & 106 \\
\hline Ureia $(46 \% \mathrm{~N})$ & $\mathrm{t}$ & 895,00 & 0,050 & 0,100 & 0,260 & 0,260 & 45 & 90 & 233 & 233 \\
\hline Sementes ${ }^{(4)}$ & $\mathrm{kg}$ & 0,54 & 200 & 175 & 120 & 120 & 108 & 94 & 65 & 65 \\
\hline \multirow[t]{2}{*}{ Total $\left(\mathrm{R} \$ \mathrm{ha}^{-1}\right)$} & & & & & & & 811 & 871 & 948 & 1.067 \\
\hline & & & \multicolumn{8}{|c|}{$2006 / 2007$} \\
\hline Glyphosate & $\mathrm{L}$ & 19,00 & 5 & 5 & 5 & 5 & 95 & 95 & 95 & 95 \\
\hline Fipronil & $\mathrm{L}$ & 375,00 & 0,300 & 0,263 & 0,180 & 0,180 & 113 & 98 & 68 & 68 \\
\hline Penoxsulan & $\mathrm{L}$ & 540,00 & 0,200 & 0,200 & 0,180 & 0,180 & 108 & 108 & 97 & 97 \\
\hline Adubo 5-20-30 & $t$ & 650,00 & 0,100 & 0,150 & 0,300 & 0,400 & 65 & 98 & 195 & 260 \\
\hline $\mathrm{KCl}$ & $\mathrm{t}$ & 750,00 & $\mathrm{n} / \mathrm{u}$ & $\mathrm{n} / \mathrm{u}$ & 0,050 & 0,050 & $\mathrm{n} / \mathrm{u}$ & $\mathrm{n} / \mathrm{u}$ & 38 & 38 \\
\hline Ureia $(46 \% \mathrm{~N})$ & $\mathrm{t}$ & 878,37 & 0,050 & 0,100 & 0,260 & 0,260 & 44 & 88 & 228 & 228 \\
\hline Sementes ${ }^{(4)}$ & $\mathrm{kg}$ & 0,58 & 200 & 175 & 120 & 120 & 115 & 101 & 69 & 69 \\
\hline Total $\left(\mathrm{R} \$ \mathrm{ha}^{-1}\right)$ & & & & & & & 540 & 588 & 790 & 855 \\
\hline
\end{tabular}

(1) $\mathrm{Na}$ época preferencial, as semeaduras foram realizadas em 5/11/2003, 29/10/2004 e 27/10/2006, e, na época tardia, foram realizadas em 3/12/2003, 3/12/2004 e 13/12/2006; para as duas épocas de semeadura foram utilizados os mesmos preços dos insumos. (2)Os sistemas de práticas de manejo diferenciaram-se quanto à densidade de semeadura, à adubação de base e de cobertura, à dose de herbicida usada e aos manejos da adubação de cobertura e da irrigação (Tabela 1). ${ }^{(3)}$ Não utilizado. ${ }^{(4)}$ Cultivar IRGA 420. 
levantamento de preços realizada pelo IRGA. Para facilitar o entendimento do texto, a expressão margem de contribuição parcial será substituída por análise financeira.

\section{Resultados e Discussão}

Para produtividade de grãos, houve interação tríplice entre estação de crescimento, época de semeadura e sistemas de práticas de manejo (Tabela 3 ). $\mathrm{Na}$ época de semeadura preferencial, na primeira estação de crescimento, a produtividade aumentou até o uso do sistema de práticas de manejo alto, enquanto nas outras duas estações o aumento ocorreu até o sistema de práticas de manejo muito alto. Já na época de semeadura tardia, no primeiro e segundo anos observou-se aumento da produtividade até o sistema de práticas de manejo médio, enquanto no terceiro ano o aumento ocorreu até o sistema de práticas de manejo alto.

As diferenças de produtividades de grãos observadas entre sistemas de práticas de manejo são decorrentes principalmente da variação e da integração das práticas de manejo utilizadas (Tabela 1). Além de os sistemas diferirem quanto às doses de adubo aplicadas na semeadura e em cobertura, houve diferença também quanto à época da adubação de cobertura e ao início da irrigação. Nos sistemas de práticas de manejo baixo e médio, utilizou-se menor quantidade de adubo nitrogenado em cobertura, a aplicação foi feita em época inadequada e atrasou-se o início da irrigação, fatores que contribuíram para a redução da produtividade de grãos.

A resposta à melhoria no manejo da cultura na época de semeadura tardia foi menor que a observada na época preferencial. O aumento da produtividade de grãos na época de semeadura preferencial, na média dos três anos, foi de $65 \%$, enquanto na época tardia foi de $29 \%$. Em estudo semelhante realizado com a cultura do milho, Forsthofer et al. (2006) observaram maior resposta à melhoria no manejo nas épocas de semeadura precoce (agosto) e preferencial (outubro) em relação à semeadura tardia (dezembro), evidenciando a interação entre sistemas de práticas de manejo e época de semeadura.

Nas safras 2004/2005 e 2006/2007, além da maior resposta à melhoria no sistema de práticas de manejo na época de semeadura preferencial, as produtividades de grãos foram maiores que na época de semeadura tardia, independentemente do sistema de práticas de manejo, exceto nos sistemas de práticas de manejo baixo e médio na primeira estação de crescimento. Essa maior produtividade é devido à coincidência dos períodos reprodutivo e de formação e enchimento de grãos com os dias de maior disponibilidade de radiação solar (Figura 1). Durante essas fases de desenvolvimento da planta, a disponibilidade de radiação solar é o principal determinante da formação de grãos de pólen e da fertilização de espiguetas de arroz (Vijayalakshmi et al., 1991).

Quando a semeadura é realizada na época tardia, além da limitação imposta pela menor disponibilidade de radiação solar, a ocorrência de baixas temperaturas durante o período reprodutivo também pode contribuir para a redução da produtividade de grãos e da resposta à melhoria do sistema de práticas de manejo (Figura 1). O efeito prejudicial de temperaturas baixas é maior quando ocorre no período que antecede imediatamente a floração (estádio $\mathrm{R}_{2}$ ), ou seja, na microsporogênese, quando se formam os grãos de pólen (Cruz \& Milach, 2000).

Outro fator que pode ter contribuído para diminuir a produtividade de grãos e a resposta à melhoria do manejo na época de semeadura tardia pode estar associado à

Tabela 3. Produtividade $\left(\mathrm{kg} \mathrm{ha}^{-1}\right)$ de grãos de arroz irrigado em função de estação de crescimento, época de semeadura e sistema de práticas de manejo em Cachoeirinha, $\mathrm{RS}^{(1)}$.

\begin{tabular}{|c|c|c|c|c|c|}
\hline \multirow[t]{2}{*}{ Estação de crescimento } & \multirow[t]{2}{*}{ Época de semeadura $^{(2)}$} & \multicolumn{4}{|c|}{ Sistemas de práticas de manejo $^{(3)}$} \\
\hline & & Baixo & Médio & Alto & Muito alto \\
\hline \multirow[t]{2}{*}{$2003 / 2004$} & Preferencial & $5.768 \mathrm{~B}(\mathrm{~B}) \mathrm{c}$ & $6.468 \mathrm{~B}(\mathrm{~B}) \mathrm{b}$ & $11.922 \mathrm{~A}(\mathrm{~A}) \mathrm{a}$ & $12.176 \mathrm{~A}(\mathrm{~A}) \mathrm{a}$ \\
\hline & Tardia & $6.837 \mathrm{~B}(\mathrm{~A})(\mathrm{a})$ & $7.570 \mathrm{AB}(\mathrm{A})(\mathrm{a})$ & $6.845 \mathrm{~B}(\mathrm{~B})(\mathrm{b})$ & $8.486 \mathrm{~A}(\mathrm{~B})(\mathrm{a})$ \\
\hline \multirow[t]{2}{*}{$2004 / 2005$} & Preferencial & $8.109 \mathrm{C}(\mathrm{A}) \mathrm{a}$ & $9.280 \mathrm{~B}(\mathrm{~A}) \mathrm{a}$ & $10.107 \mathrm{~B}(\mathrm{~A}) \mathrm{b}$ & $12.242 \mathrm{~A}(\mathrm{~A}) \mathrm{a}$ \\
\hline & Tardia & $6.563 \mathrm{C}(\mathrm{B})(\mathrm{a})$ & $8.405 \mathrm{AB}(\mathrm{B})(\mathrm{a})$ & $8.133 \mathrm{~B}(\mathrm{~B})(\mathrm{a})$ & $9.135 \mathrm{~A}(\mathrm{~B})(\mathrm{a})$ \\
\hline \multirow[t]{2}{*}{$2006 / 2007$} & Preferencial & $6.777 \mathrm{C}(\mathrm{A}) \mathrm{b}$ & $8.755 \mathrm{~B}(\mathrm{~A}) \mathrm{a}$ & $8.671 \mathrm{~B}(\mathrm{~A}) \mathrm{c}$ & $9.819 \mathrm{~A}(\mathrm{~A}) \mathrm{b}$ \\
\hline & Tardia & $4.213 \mathrm{C}(\mathrm{B})(\mathrm{b})$ & $4.812 \mathrm{BC}(\mathrm{B})(\mathrm{b})$ & $6.306 \mathrm{~A}(\mathrm{~B})(\mathrm{b})$ & $5.743 \mathrm{AB}(\mathrm{B})(\mathrm{b})$ \\
\hline
\end{tabular}

${ }^{(1)}$ Médias seguidas de letras iguais não diferem entre si pelo teste de Duncan, a 5\% de probabilidade: letras maiúsculas na linha comparam os sistemas de práticas de manejo dentro de cada época de semeadura e de cada ano; letras maiúsculas entre parênteses na coluna comparam as épocas de semeadura dentro de cada sistema de práticas de manejo e de cada ano; letras minúsculas na coluna comparam as médias da época preferencial dentro de cada sistema de práticas de manejo entre as estações de crescimento; letras minúsculas entre parênteses comparam as médias da época tardia dentro de cada sistema de práticas de manejo entre as estações de crescimento; o coeficiente de variação foi 8,3\%. ${ }^{(2)} \mathrm{Na}$ época preferencial, as semeaduras foram realizadas em 5/11/2003, 29/10/2004 e 27/10/2006, e, na época tardia, foram realizadas em 3/12/2003, 3/12/2004 e 13/12/2006. ${ }^{(3)}$ Os sistemas de práticas de manejo diferenciaram-se quanto à densidade de semeadura, à adubação de base e de cobertura, à dose de herbicida usada e aos manejos da adubação de cobertura e da irrigação (Tabela 1). 
eficiência de uso do adubo nitrogenado nessa época. Ao realizar experimento no mesmo local, Freitas et al. (2008) observaram que a eficiência agronômica do nitrogênio aplicado em arroz irrigado é menor na época tardia de semeadura( 9 dedezembro)emrelação àépocapreferencial ( 2 de outubro), chegando a 70 e $85 \%$, respectivamente, com as doses de 60 e $120 \mathrm{~kg} \mathrm{ha}^{-1}$ e próximo a $0 \%$ com a aplicação de $180 \mathrm{~kg} \mathrm{ha}^{-1}$.

O aumento da produtividade de grãos é fundamental para a obtenção de lucros que permitam ao produtor permanecer em atividade, principalmente quando esse aumento é oriundo de melhorias nas práticas de manejo que têm pouco ou nenhum custo (Sangoi et al., 2003). A escolha da época de semeadura não requer investimento para sua implementação e é uma estratégia capaz de exercer grande efeito sobre o desempenho técnicofinanceiro das culturas.

$\mathrm{Na}$ análise financeira, o primeiro ponto relevante foi a época de semeadura. Independentemente do sistema de práticas de manejo e da estação de crescimento, a época preferencial apresentou resultados financeiros superiores (Tabela 4). Além disso, o sistema de práticas

Tabela 4. Receita, custo operacional e retorno financeiro do arroz irrigado em função de época de semeadura (preferencial e tardia) e sistema de práticas de manejo em três estações de crescimento em Cachoeirinha, $\mathrm{RS}^{(1)}$.

\begin{tabular}{|c|c|c|c|c|c|c|c|c|}
\hline \multirow[t]{2}{*}{ Itens } & \multicolumn{4}{|c|}{ Sistemas de práticas de manejo/época preferencial } & \multicolumn{4}{|c|}{ Sistemas de práticas de manejo/época tardia } \\
\hline & Baixo & Médio & Alto & Muito alto & Baixo & Médio & Alto & Muito alto \\
\hline & \multicolumn{8}{|c|}{$2003 / 2004$} \\
\hline Produtividade de grãos $\left(\mathrm{kg} \mathrm{ha}^{-1}\right)$ & 5.768 & 6.468 & 11.922 & 12.176 & 6.837 & 7.570 & 6.845 & 8.486 \\
\hline Preço de venda ( $\mathrm{R} \$$ por saco) & 31,04 & 31,04 & 31,04 & 31,04 & 29,55 & 29,55 & 29,55 & 29,55 \\
\hline Receita $\left(\mathrm{R} \$ \mathrm{ha}^{-1}\right)$ & 3.581 & 4.015 & 7.401 & 7.559 & 4.041 & 4.474 & 4.045 & 5.015 \\
\hline Dessecante & 91 & 91 & 91 & 91 & 91 & 91 & 91 & 91 \\
\hline Sementes & 170 & 148 & 102 & 102 & 170 & 148 & 102 & 102 \\
\hline Fertilizantes & 105 & 175 & 393 & 503 & 105 & 175 & 393 & 503 \\
\hline Agroquímicos & 401 & 388 & 253 & 253 & 401 & 388 & 253 & 253 \\
\hline Operações tratos culturais & 50 & 57 & 58 & 61 & 50 & 57 & 58 & 61 \\
\hline Operações de colheita & 358 & 402 & 740 & 756 & 404 & 447 & 405 & 502 \\
\hline Operações de transporte & 57 & 64 & 118 & 121 & 65 & 72 & 65 & 80 \\
\hline Operações de secagem & 215 & 241 & 444 & 454 & 242 & 268 & 243 & 301 \\
\hline Custos considerados $\left(\mathrm{R} \$ \mathrm{ha}^{-1}\right)$ & 1.446 & 1.566 & 2.200 & 2.339 & 1.527 & 1.646 & 1.609 & 1.892 \\
\hline \multirow[t]{2}{*}{ Retorno financeiro $\left(\mathrm{R} \$ \mathrm{ha}^{-1}\right)$} & 2.135 & 2.450 & 5.202 & 5.219 & 2.514 & 2.827 & 2.436 & 3.123 \\
\hline & \multicolumn{8}{|c|}{$2004 / 2005$} \\
\hline Produtividade de grãos $\left(\mathrm{kg} \mathrm{ha}^{-1}\right)$ & 8.109 & 9.280 & 10.107 & 11.902 & 6.564 & 8.405 & 7.948 & 9.121 \\
\hline Preço de venda ( $\mathrm{R} \$$ por saco) & 20,32 & 20,32 & 20,32 & 20,32 & 18,14 & 18,14 & 18,14 & 18,14 \\
\hline Receita $\left(\mathrm{R} \$ \mathrm{ha}^{-1}\right)$ & 3.295 & 3.771 & 4.107 & 4.837 & 2.381 & 3.049 & 2.884 & 3.309 \\
\hline Dessecante & 100 & 100 & 100 & 100 & 100 & 100 & 100 & 100 \\
\hline Sementes & 108 & 94 & 65 & 65 & 108 & 94 & 65 & 65 \\
\hline Fertilizantes & 129 & 216 & 487 & 605 & 129 & 216 & 487 & 605 \\
\hline Agroquímicos & 474 & 460 & 297 & 297 & 474 & 460 & 297 & 297 \\
\hline Operações tratos culturais & 61 & 68 & 70 & 73 & 61 & 68 & 70 & 73 \\
\hline Operações de colheita & 330 & 377 & 411 & 484 & 238 & 305 & 288 & 331 \\
\hline Operações de transporte & 66 & 75 & 82 & 97 & 48 & 61 & 58 & 66 \\
\hline Operações de secagem & 198 & 226 & 246 & 290 & 143 & 183 & 173 & 199 \\
\hline Custos considerados $\left(\mathrm{R} \$ \mathrm{ha}^{-1}\right)$ & 1.465 & 1.618 & 1.757 & 2.010 & 1.300 & 1.488 & 1.537 & 1.735 \\
\hline \multirow[t]{2}{*}{ Retorno financeiro $\left(\mathrm{R} \$ \mathrm{ha}^{-1}\right)$} & 1.831 & 2.153 & 2.350 & 2.827 & 1.081 & 1.561 & 1.347 & 1.574 \\
\hline & \multicolumn{8}{|c|}{$2006 / 2007$} \\
\hline Produtividade de grãos $\left(\mathrm{kg} \mathrm{ha}^{-1}\right)$ & 6.777 & 8.754 & 8.671 & 9.819 & 4.213 & 4.812 & 6.306 & 5.552 \\
\hline Preço de venda (R\$ por saco) & 20,13 & 20,13 & 20,13 & 20,13 & 21,08 & 21,08 & 21,08 & 21,08 \\
\hline Receita $\left(\mathrm{R} \$\right.$ ha $\left.^{-1}\right)$ & 2.728 & 3.524 & 3.491 & 3.953 & 1.776 & 2.029 & 2.659 & 2.341 \\
\hline Dessecante & 95 & 95 & 95 & 95 & 95 & 95 & 95 & 95 \\
\hline Sementes & 115 & 101 & 69 & 69 & 115 & 101 & 69 & 69 \\
\hline Fertilizantes & 109 & 185 & 461 & 526 & 109 & 185 & 461 & 526 \\
\hline Agroquímicos & 221 & 206 & 165 & 165 & 221 & 206 & 165 & 165 \\
\hline Operações tratos culturais & 62 & 70 & 71 & 75 & 62 & 70 & 71 & 75 \\
\hline Operações de colheita & 273 & 352 & 349 & 395 & 178 & 203 & 266 & 234 \\
\hline Operações de transporte & 65 & 85 & 84 & 95 & 43 & 49 & 64 & 56 \\
\hline Operações de secagem & 164 & 211 & 209 & 237 & 107 & 122 & 160 & 140 \\
\hline Custos considerados $\left(\mathrm{R} \$ \mathrm{ha}^{-1}\right)$ & 1.104 & 1.306 & 1.504 & 1.657 & 928 & 1.031 & 1.350 & 1.360 \\
\hline Retorno financeiro $\left(\mathrm{R} \$ \mathrm{ha}^{-1}\right)$ & 1.625 & 2.218 & 1.987 & 2.296 & 848 & 998 & 1.308 & 980 \\
\hline
\end{tabular}

(1) $\mathrm{Na}$ época preferencial, as semeaduras foram realizadas em 5/11/2003, 29/10/2004 e 27/10/2006, e, na época tardia, foram realizadas em 3/12/2003, 3/12/2004 e 13/12/2006; para as duas épocas de semeadura foram utilizados os mesmos preços dos insumos; os sistemas de práticas de manejo diferenciaram-se quanto à densidade de semeadura, à adubação de base e de cobertura, à dose de herbicida usada e aos manejos da adubação de cobertura e da irrigação (Tabela 1). 
de manejo baixo, na época de semeadura preferencial, resultou em maior retorno financeiro em relação ao obtido nos sistemas de práticas de manejo baixo, médio e alto na época tardia, e muito próximo ao verificado no sistema de práticas de manejo muito alto na época tardia, ou seja, o cultivo do arroz na época preferencial determinou resultados financeiros mais positivos.

Outro ponto relevante na análise financeira foi o fato de que o retorno financeiro na época preferencial aumentou de forma acentuada com o uso do sistema de práticas de manejo alto. Houve apenas pequeno incremento quando se aplicou o sistema de práticas de manejo muito alto. Já na época tardia, foram verificados menores incrementos do retorno financeiro à medida que o manejo foi melhorado (Figura 2). Nas duas épocas de semeadura houve redução de custos com sementes e herbicidas, devido ao uso de menores quantidades desses insumos por hectare com a melhoria das técnicas de manejo. Independentemente do sistema de práticas de manejo, 60 a 70\% dos custos de produção de uma

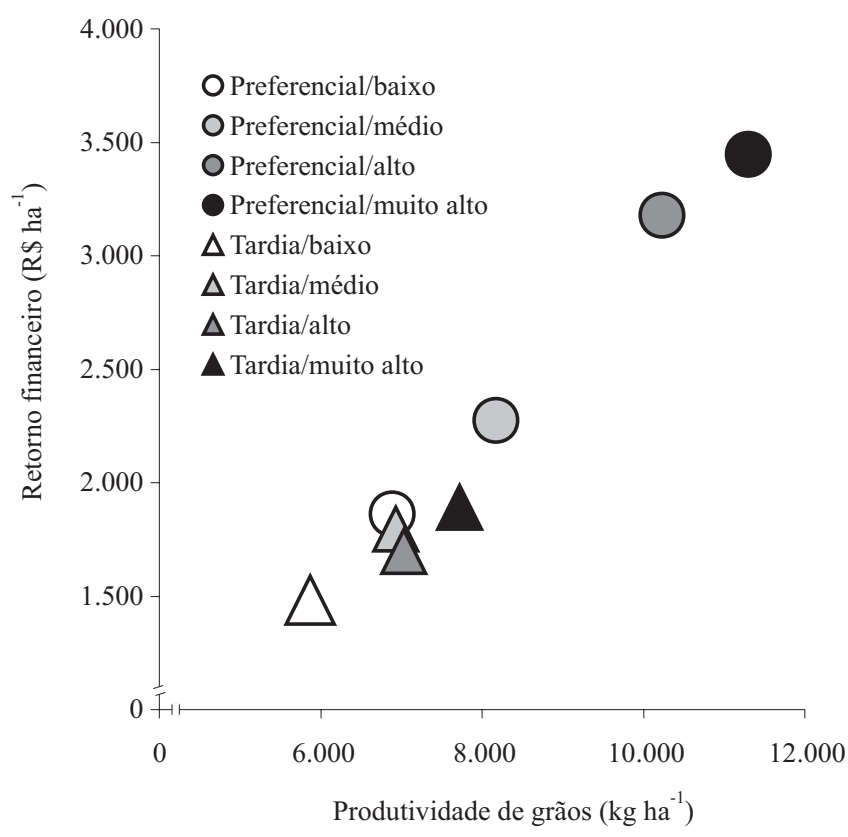

Figura 2. Produtividade de grãos e retorno financeiro de arroz irrigado cultivado em quatro sistemas de práticas de manejo (baixo, médio, alto e muito alto, conforme descrito na Tabela 1), em duas épocas de semeadura (preferencial: 5/11/2003, 29/10/2004 e 27/10/2006 e tardia: 3/12/2003, $3 / 12 / 2004$ e 13/12/2006), na média de três estações de crescimento (2003/2004, 2004/2005 e 2006/2007) em Cachoeirinha, RS. lavoura de arroz irrigado não variam em função da produtividade esperada (Menezes et al., 2004).

O melhor resultado financeiro ocorreu com a combinação da época preferencial e sistema de manejo muito alto, seguido da época preferencial e manejo alto, época preferencial e manejo médio, época tardia e manejo muito alto, época preferencial e manejo baixo, época tardia e manejo médio, época tardia e manejo alto e época tardia e manejo baixo. Em todas as combinações utilizadas na análise, o retorno financeiro foi positivo. $\mathrm{Na}$ média das três estações de crescimento, o maior valor foi de $\mathrm{R} \$ 3.447,00$ por hectare e o menor, de $\mathrm{R} \$ 1.481,00$ por hectare.

Pode-se considerar que, independentemente do sistema de práticas de manejo adotado, a época de semeadura preferencial apresentou resultados financeiros mais satisfatórios que a época tardia. Também, a melhoria no manejo adotado proporcionou retorno financeiro maior. Com a combinação desses dois fatores os resultados são mais favoráveis em termos de eficiência financeira. Esses resultados corroboram os obtidos por Forsthofer et al. (2006) na cultura do milho, em que a melhoria no manejo proporcionou maior retorno financeiro nas épocas de semeadura precoce e intermediária em relação à tardia, sendo possível associar as máximas eficiências técnica e financeira às épocas precoce e intermediária.

A melhoria nos sistemas de práticas de manejo mostra-se viável sob os aspectos técnico-financeiros e resulta também em benefícios ambientais. Com a melhoria no manejo (alto e muito alto), a entrada da água definitiva nas parcelas ocorreu mais cedo no ciclo de desenvolvimento da planta em relação aos sistemas de práticas de manejo baixo e médio. Resultados de pesquisa evidenciam que a entrada precoce da água aumenta a eficiência de seu uso em relação à entrada mais tardia (Menezes et al., 2004). Outra vantagem da entrada precoce da água relaciona-se ao controle de plantas daninhas, uma vez que viabiliza o uso de menor dose de herbicidas, contribuindo para diminuir a contaminação de mananciais. Com relação às épocas de semeadura, tem-se observado maior eficiência de uso de nitrogênio na época preferencial em relação à tardia (Freitas et al., 2008), o que contribui para a redução de perdas de nitrogênio e contaminação do 
ambiente. Dessa maneira, a melhoria no manejo da cultura do arroz irrigado não implica necessariamente maior risco de poluição do ambiente devido ao uso de mais insumos, exceto o adubo, sendo, portanto, favorável dos pontos de vista agronômico, financeiro e ambiental.

\section{Conclusões}

1. A resposta em produtividade de grãos e em retorno financeiro do arroz irrigado à melhoria do sistema de práticas de manejo é maior na época de semeadura preferencial do que na tardia.

2. A maior produtividade de grãos e os menores custos com sementes e herbicidas nos sistemas de práticas de manejo com uso de mais tecnologia, na época preferencial, resultam em maiores retornos financeiros.

\section{Agradecimentos}

Ao Conselho Nacional de Desenvolvimento Científico e Tecnológico, pelas bolsas concedidas.

\section{Referências}

ARGENTA, G.; SANGOI, L.; SILVA, P.R.F. da; RAMPAZZO, C.; GRACIETTI, L.C.; STRIEDER, M.L.; FORSTHOFER, E.L.; SUHRE, E. Potencial de rendimento de grãos de milho em dois ambientes e cinco sistemas de produção. Scientia Agraria, v.4, p.27-34, 2003.

CARMONA, R. de C.; SILVA, P.R.F. da; FREITAS, T.F.S. de; STRIEDER, M.L.; MARIOT, C.H.P. Influência de cultivares, densidades de semeadura e doses de nitrogênio na produção integrada de arroz e peixes. Ciência Rural, v.38, p.811-814, 2008 .

COUNCE, P.A.; KEISLING, T.C.; MITCHELL, A.J. A uniform, objective, and adaptive system for expressing rice development. Crop Science, v.40, p.436-443, 2000.

CRUZ, R.P. da; MILACH, S.C.K. Melhoramento genético para tolerância ao frio em arroz irrigado. Ciência Rural, v.30, p.909-917, 2000.

FAGI, A.M.; DE DATTA, S.K. Environmental factors affecting nitrogen efficiency in flooded tropical rice. Nutrient Cycling in Agroecosystems, v.2, p.53-67, 1981.
FORSTHOFER, E.L.; SILVA, P.R.F. da; STRIEDER, M.L.; MINETTO, T.; RAMBO, L.; ARGENTA, G.; SANGOI, L.; SUHRE, E.; SILVA, A.A. da. Desempenho agronômico e econômico do milho em diferentes níveis de manejo e épocas de semeadura. Pesquisa Agropecuária Brasileira, v.41, p.399-407, 2006.

FREITAS, T.F.S. de; SILVA, P.R.F da; MARIOT, C.H.P.; MENEZES, V.G.; ANGHINONI, I.; BREDEMEIER, C.; VIEIRA, V.M. Produtividade de arroz irrigado e eficiência da adubação nitrogenada influenciadas pela época da semeadura. Revista Brasileira de Ciência do Solo, v.32, p.2397-2405, 2008.

FREITAS, T.F.S. de; SILVA, P.R.F. da; STRIEDER, M.L.; SILVA, A.A. da. Validação de escala de desenvolvimento para cultivares brasileiras de arroz irrigado. Ciência Rural, v.36, p.404-410, 2006.

IRGA. Censo da lavoura de arroz irrigado do Rio Grande do Sul: safra 2004/2005. Porto Alegre: IRGA, 2006. 122p.

IUDÍCIBUS, S. de; MARION, J.C. Manual de contabilidade para não contadores. 2.ed. São Paulo: Atlas, 1990.

MARIOT, C.H.P.; SILVA, P.R.F da; MENEZES, V.G.; TEICHMANN, L.L. Resposta de duas cultivares de arroz irrigado à densidade de semeadura e à adubação nitrogenada. Pesquisa Agropecuária Brasileira, v.38, p.233-241, 2003.

MENEZES, V.G.; MACEDO, V.R.M.; ANGHINONI, I. Projeto 10: estratégias de manejo para o aumento de produtividade, competitividade e sustentabilidade da lavoura de arroz irrigado no RS. Cachoeirinha: IRGA, 2004. 32p.

SANGOI, L.; ARGENTA, G.; SILVA, P.R.F. da; MINETTO, T.J.; BISOTTO, V. Níveis de manejo na cultura do milho em dois ambientes contrastantes: análise técnico-econômica. Ciência Rural, v.33, p.1021-1029, 2003.

SANTOS, H.G. dos; JACOMINE, P.K.T.; ANJOS, L.H.C. dos; OLIVEIRA, V.A. de; OLIVEIRA, J.B. de; COELHO, M.R.; LUMBRERAS, J.F.; CUNHA, T.J.F. (Ed.). Sistema brasileiro de classificação de solos. 2.ed. Rio de Janeiro: Embrapa Solos, 2006. $306 \mathrm{p}$.

SLATON, N.A.; LINSCOMBE, S.D.; NORMAN, R.J.; GBUR JÚNIOR, E.E. Seeding date effect on rice grain yields in Arkansas and Louisiana. Agronomy Journal, v.95, p.218-223, 2003.

SOCIEDADE SUL-BRASILEIRA DE ARROZ IRRIGADO. Arroz irrigado: recomendações técnicas da pesquisa para o Sul do Brasil. Pelotas: Sosbai, 2007. 154p.

VIJAYALAKSHMI, C.; RADHAKRISHNAN, R.; NAGARAJAN, M.; RAJENDRAN, C. Effect of solar radiation deficit on rice productivity. Journal of Agronomy and Crop Science, v.167, p.184-187, 1991.

Recebido em 28 de outubro de 2008 e aprovado em 28 de fevereiro de 2009 